\title{
Sclerosing cholangitis and combination antifungal therapy for PNP deficiency patients
}

\author{
Luis Ignacio Gonzalez-Granado
}

Received: 9 August 2009 / Accepted: 3 September 2009/Published online: 15 September 2009

(C) Springer-Verlag 2009

Sir,

I read with great interest the paper by Aytekin et al. [1] published in the last issue of the journal. I would like to make two comments. First, sclerosing cholangitis is a common condition in patients with primary immunodeficiencies [4] especially in cases of T-cell deficiency like the patients reported. However, the diagnosis is now easier since polymerase chain reaction assay in feces has become a common diagnostic procedure to rule out Cryptosporidium parvum infection in the immunocompromissed host [3]. This pathogen has been recognized as a common cause of sclerosing cholangitis and secondary cirrhosis. Azithromycin is the standard treatment for this situation (until randomized controlled trials comparing azithromycin versus nitazoxanide may change the general practice), with secondary prophylaxis once the infection has been resolved.

Second, Aspergillus infection in the immunocompromissed host has a poor outcome even with the development of new antifungal drugs. There is quite hopeful experience with combination therapy (at least with caspofungin plus voriconazole) [2]. Thus, we cannot be sure that the fatal outcome of the first patient reported could have been avoided with a combination of antifungal therapy.

Conflict of interest I declare that I have no conflict of interest.

\section{References}

1. Aytekin C, Dogu F, Tanir G et al (2009) Purine nucleoside phosphorylase deficiency with fatal course in two sisters. Eur J Pediatr (in press)

2. Marr KA, Boeckh M, Carter RA, Kim HW, Corey L (2004) Combination antifungal therapy for invasive aspergillosis. Clin Infect Dis 39:797-802

3. McLauchlin J, Amar CF, Pedraza-Díaz S et al (2003) Polymerase chain reaction-based diagnosis of infection with Cryptosporidium in children with primary immunodeficiencies. Pediatr Infect Dis J 22:329-335

4. Rodrigues F, Davies EG, Harrison P et al (2004) Liver disease in children with primary immunodeficiencies. J Pediatr 145:333-339

L. I. Gonzalez-Granado $(\bowtie)$

Immunodeficiencies Unit, Hospital Universitario 12 de Octubre,

Avenida Andalucia, km 5.4,

28041 Madrid, Spain

e-mail: nachgonzalez@gmail.com 